\title{
UTILIZAÇÃO DE BIOMASSA NA SECAGEM DE PRODUTOS AGRÍCOLAS VIA GASEIFICAÇÃO COM COMBUSTÃO ADJACENTE DOS GASES PRODUZIDOS ${ }^{1}$
}

\author{
JADIR N. SILVA ${ }^{2}$, JOSÉ CARDOSO SOBRINHO ${ }^{3}$, EMÍLIO T. SAIKI $^{4}$
}

RESUMO: Este estudo determinou a viabilidade do uso de um gaseificador/combustor que utiliza tocos de eucalipto, resíduos de serraria, cavacos de lenha e sabugo de milho como combustível na secagem de produtos agrícolas. Utilizou-se o gaseificador desenvolvido por SILVA (1988) com modificações na câmara de gaseificação; área da grelha reduzida de 0,21 para $0,06 \mathrm{~m}^{2}$; adição de um revestimento envolvendo a parte superior do gaseificador, e foi colocado um registro tipo borboleta na saída da câmara de combustão. $\mathrm{O}$ ar aquecido no combustor foi enviado para um secador que possuía câmaras metálicas que eram removíveis, içadas por um sistema de roldanas, facilitando a homogeneização da secagem. Como teste do sistema, secou-se café com umidade inicial de $54,5 \%$ bu até $11,1 \pm 1,6 \%$ bu, utilizando-se de cavacos de lenha. A temperatura do ar de secagem foi de $60^{\circ} \mathrm{C}$, pressão estática do ar na saída do ventilador de $9 \mathrm{mmca}$ e velocidade de $46,3 \mathrm{~m}^{3} \mathrm{~min}^{-1}$. Concluiu-se que o gaseificador, usando cavacos de eucalipto como combustível, consumiu entre 15,3 e18,8 $\mathrm{kg} \mathrm{h}^{-1}$ de biomassa, que o equipamento é viável para a secagem de café despolpado e para outros produtos agrícolas, não o impregnando de fumaça ou outras partículas, geradas nas fornalhas de fogo direto, e que todos os combustíveis de biomassa testados são viáveis na utilização do sistema via gasificação com adjacente combustão dos gases gerados.

PALAVRAS-CHAVE: secagem, café, alternativas energéticas.

\section{USING BIOMASS AS A FUEL FOR DRYING AGRICULTURAL PRODUCTS WITH A CLOSE COUPLED GASIFICATION/COMBUSTION SYSTEM}

SUMMARY: The main objective of this research was to verify the feasibility of the use of a close coupled biomass gasification/combustion system for drying agricultural products. It was used eucalyptus stubs, hogged wood manufacturing residue, saw dust and corncobs as fuel. A gasifier developed by SILVA (1988) was modified to handle those different types of fuel. Gasification chamber was reduced by using a smaller grate of $0.06 \mathrm{~m}^{2}$ and also a jacket was added to the top of the reactor to use residual heat. Heated air generated within combustor was mixed up with natural air to provide drying air temperature of $60{ }^{\circ} \mathrm{C}$. This system was used for drying coffee in a dryer with moveable chambers. Coffee with initial moisture of $54.5 \%$ was dried till $11.1 \%$ wet basis using wood husks for test. Air static pressure exiting fan was of $9 \mathrm{mmwc}$, at $46.3 \mathrm{~m}^{3} \mathrm{~min}^{-1}$. It was concluded that the gasifier consumed between 15.3 to $18.8 \mathrm{~kg} \mathrm{~h}^{-1}$ of biomass; the equipment is viable for drying pulped coffee and consequently other agricultural products because it does generate clean hot air that will not pollute the product with smoke or particulate, and, also that all four types of biomass tested are viable to be used as fuel in a gasification/combustion system for drying agricultural products.

KEYWORDS: coffee, drying agricultural products, biomass and gasification.

\footnotetext{
${ }^{1}$ Trabalho apresentado no CONBEA 2002, Salvador - BA.

${ }^{2}$ Matemático, Prof. Titular, Departamento de Engenharia Agrícola e Ambiental, Centro de Ciências Agrárias, UFV, Viçosa - MG, Fone: (0XX31) 899.1928, e-mail jadir@ufv.br

${ }^{3}$ Eng. Agrícola, Prof. Adjunto, Departamento de Engenharia de Produção Agroindustrial, Campus Toledo, PUCPR, Toledo - PR, Fone: (0XX45) 277.8600, e-mail jcardoso@ rla01.pucpr.br

${ }^{4}$ Eng. Florestal, estudante do Programa de Pós-Graduação em Engenharia Agrícola, Departamento de Engenharia Agrícola, UFV.

Recebido pelo Conselho Editorial em: 30-4-2002

Aprovado pelo Conselho Editorial em: 22-3-2004
} 


\section{INTRODUÇÃO}

Nos países em vias de desenvolvimento, a biomassa é uma importante fonte de energia. Principalmente em áreas rurais, a utilização da biomassa é, por vezes, a forma mais barata de produzir eletricidade ou ar quente para secagem de produtos agrícolas. Atualmente, a maioria dos sistemas que estão sendo utilizados para a produção de calor a partir de biomassa, tem baixa eficiência, como consequiência das características do combustível, bem como da pequena dimensão das centrais de produção.

A gaseificação é um processo endotérmico em que um combustível sólido, biomassa, por exemplo, é convertido num gás de baixa ou média capacidade calorífica. Os gaseificadores de leito fixo e fluidizado são os indicados para sistemas de produção de energia a partir de biomassa. $\mathrm{O}$ oxidante para o processo de gasificação pode ser o ar atmosférico ou oxigênio puro. Os sistemas que utilizam oxigênio puro permitem produzir um gás de maior capacidade calorífica, sendo também mais rápida a sua produção; no entanto, os custos de produção aumentam devido à necessidade de oxigênio puro.

Atualmente, o equipamento preferido é o gaseificador alimentado com ar, que produz um gás diluído com azoto atmosférico.

Gaseificação é um processo de oxidação parcial controlada de um combustível sólido, pela conversão da biomassa, ou de qualquer combustível sólido, em um gás energético. $\mathrm{O}$ uso da gaseificação da biomassa no Brasil é uma prática ainda não difundida ou utilizada pelos produtores na secagem de produtos agrícolas, principalmente pela tecnologia que demanda e especialmente pela falta de divulgação dessa prática.

A gaseificação oferece aos usuários dessa técnica as seguintes vantagens: 1) alta eficiência térmica, variando de $60 \%$ a $90 \%$, dependendo do sistema implementado; 2 ) a energia produzida com a queima dos gases produzido é limpa; 3 ) os grãos secos não são contaminados por fumaças ou gases; 4) a demanda de energia pode ser controlada e, conseqüentemente, a taxa de gaseificação pode ser facilmente monitorada e, também, controlada. As desvantagens são: 1) a biomassa deverá ser limpa, sem a presença de terras ou outros elementos que possam comprometer o processo de gaseificação; 2) há o potencial de fusão de cinzas, que poderá alterar o desempenho do gaseificador, quando se usa a biomassa com alto teor de cinzas, e 4) se não completamente queimado, o alcatrão, formado durante o processo de gaseificação, pode limitar suas aplicações.

O objetivo deste trabalho foi o de testar vários tipos de combustíveis de biomassa em um conjunto gaseificador/combustor, visando à sua utilização como fonte de energia para o aquecimento do ar de secagem, bem como a analisar os parâmetros de gaseificação e ao desempenho do conjunto como um todo.

\section{MATERIAL E MÉTODOS}

$\mathrm{O}$ experimento foi realizado no setor de armazenamento do Departamento de Engenharia Agrícola da Universidade Federal de Viçosa, Viçosa - MG, com o objetivo de testar a viabilidade do uso de um gaseificador/combustor, acoplado a um secador de leito fixo, na secagem de café despolpado, com aquecimento do ar de secagem a fogo direto. Usou-se um gaseificador desenvolvido por SILVA (1988), com modificações na câmara de gaseificação. A área da grelha foi reduzida para $0,06 \mathrm{~m}^{2}$, havendo também a adição de um revestimento envolvendo o gaseificador para aproveitamento do calor que antes era dissipado à atmosfera e um registro tipo borboleta na saída da câmara de combustão do gás, para regular a vazão de ar aquecido. O secador de leito fixo utilizado foi construído por CAMPOS (1998), possuindo quatro câmaras metálicas, dotadas de movimentação e içadas por um sistema de roldanas e cabos. 
Na Figura 1, ilustra-se o sistema gaseificador/combustor e, na Figura 2, os detalhes do sistema construído.

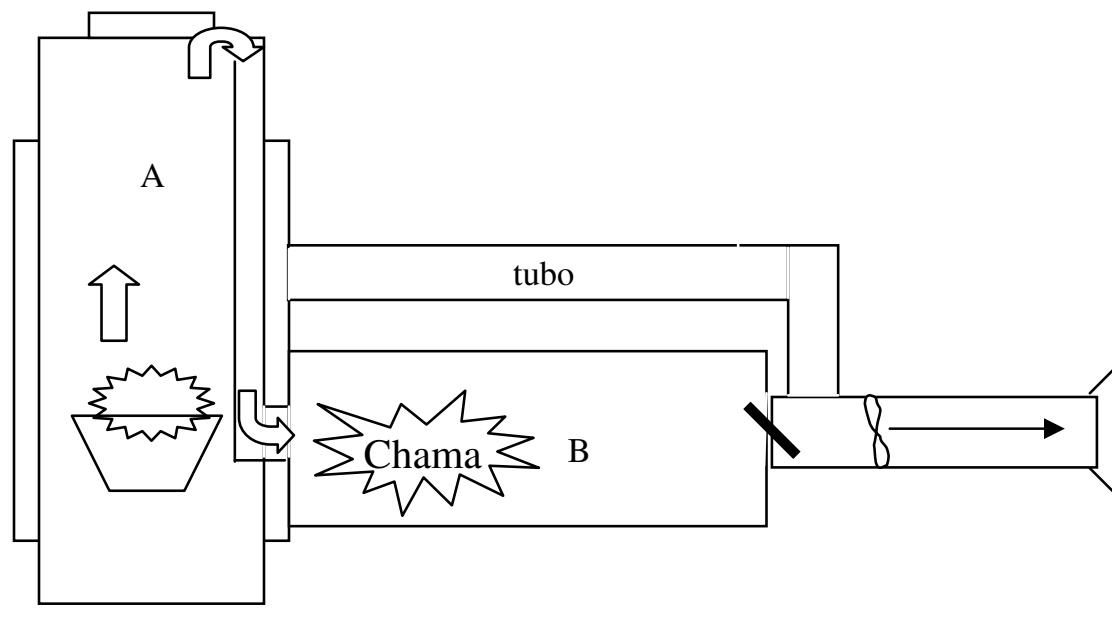

A - gaseificador

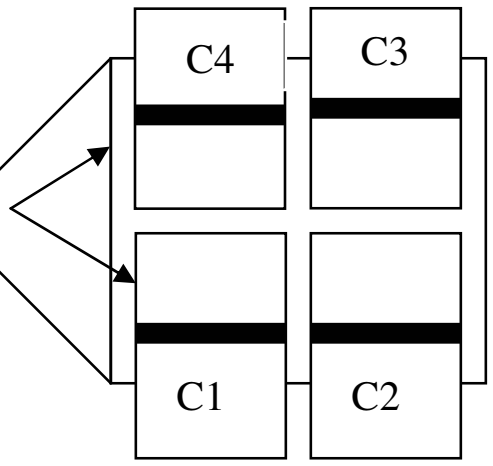

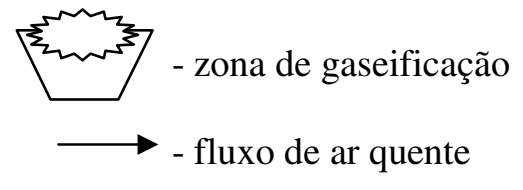

$\widehat{U}$ - fluxo dos gases produzidos
C1, C2, C3 e C4 - câmaras de secagem usadas

\& - registro tipo borboleta

B - câmara de combustão dos gases

FIGURA 1. Croqui do sistema gaseificador/combustor utilizado para o aquecimento do ar de secagem.

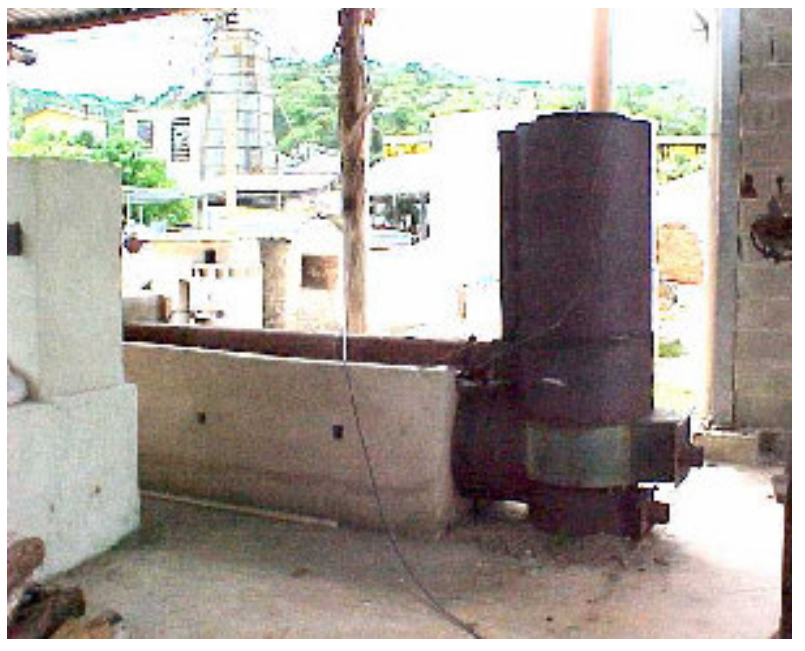

(a)

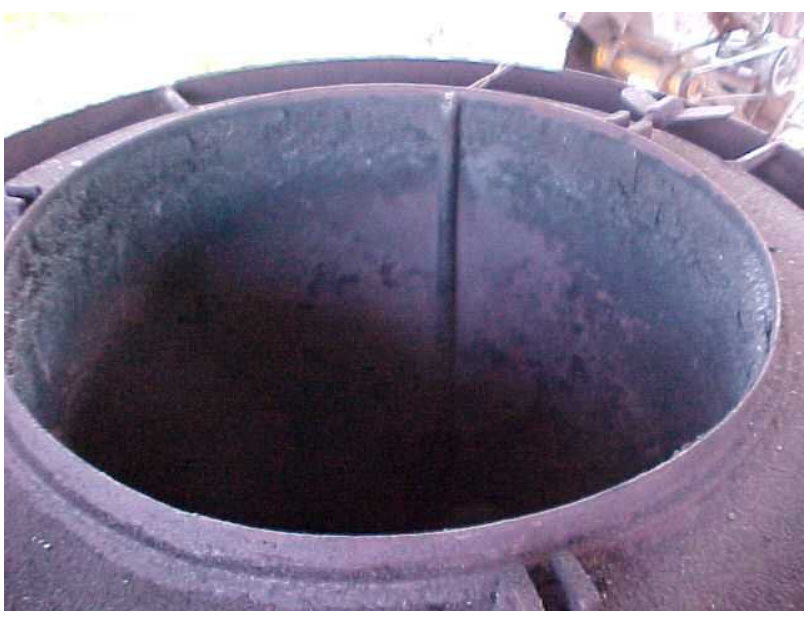

(b)

FIGURA 2. Vista frontal do sistema gaseificador/combustor utilizado na secagem (a) e detalhes do sistema construído (b).

Secou-se café com umidade inicial de $54,4 \%$ bu até $11,1 \pm 1,6 \%$ bu. A determinação da umidade do produto foi realizada no início da operação na estufa; no final realizou-se no determinador Universal, no EDABO (Evaporação Direta de Água em Banho de Óleo) e conferidos na estufa. Utilizaram-se secadores de camada fixa com revolvimento do produto em intervalos regulares de três horas. 
A temperatura do ar de secagem, pressão estática e velocidade do ar aquecido foram de $60{ }^{\circ} \mathrm{C}$, 9 mmca e 46,3 $\mathrm{m}^{3} \mathrm{~min}^{-1}$, respectivamente. Foram utilizados, como combustível, cavacos de eucalipto usados na produção de papel e celulose, com dois valores de umidade 17,8 e 9,0\% bu. O poder calorífico dos cavacos foi determinado conforme a sua umidade inicial, considerando o poder calorífico superior do Eucalyptus grandis de $17.974 \mathrm{~kJ} \mathrm{~kg}^{-1}$.

O ar limpo e seco só foi direcionado ao café a ser secado quando a combustão dos gases atingiu o processo em regime permanente. Isso foi conseguido adaptando-se ao sistema uma saída lateral, a fim de retirar a fumaça impura formada no início do processo, impedindo, assim, que o produto fosse contaminado.

Durante os ensaios, foram retiradas amostras do produto em intervalos regulares de três horas, para a determinação da curva de secagem do café. Testes posteriores de desempenho do sistema gaseificador/combustor foram feitos também com os outros combustíveis citados; no entanto, não foram realizadas secagens nesses testes por falta do café, tendo em vista o fim da safra.

Balanços de massa e energia foram a base para a determinação da eficiência do sistema. A eficiência do sistema é a razão entre a energia pretendida e a energia gasta (WYLEN et al., 1998). A energia pretendida é a energia do ar de secagem, e a energia gasta é o calor produzido pela queima do combustível e a energia elétrica consumida.

$$
\eta=\frac{E_{\text {pretendida }}}{E_{\text {gasta }}}
$$

A eficiência no gaseificador/combustor foi estimada, então, segundo a eq.(2):

$$
\eta_{\mathrm{GC}}=\frac{\dot{\mathrm{m}}_{\mathrm{g}}\left(\mathrm{h}_{\mathrm{g}}+\frac{\mathrm{v}_{\mathrm{g}}^{2}}{2000}\right)}{\left.\dot{\mathrm{m}} \mathrm{b}^{\mathrm{PCI}}\right)+\dot{\mathrm{W}}_{\mathrm{GC}}}
$$

em que,

ๆGC - eficiência do gaseificador/combustor, decimal;

$\dot{\mathrm{m}}_{\mathrm{g}}$ - fluxos de massas dos gases de exaustão, $\mathrm{kg} \mathrm{h}^{-1}$;

m $\mathrm{b}$ - vazão mássica da massa da biomassa, $\mathrm{kg} \mathrm{h}^{-1}$;

$\mathrm{h}_{\mathrm{g}}$ - entalpia dos gases de exaustão, $\mathrm{kJ} \mathrm{kg}^{-1}$;

$\mathrm{V}_{\mathrm{g}}$ - velocidade dos gases, $\mathrm{m} \mathrm{s}^{-1}$;

PCI - poder calorífico inferior da biomassa, $\mathrm{kJ} \mathrm{kg}^{-1}$, e

$\dot{\mathrm{w}}_{\mathrm{GC}}$ - potência requerida pelo ventilador, $\mathrm{kJ} \mathrm{h}^{-1}$.

\section{RESULTADOS E DISCUSSSÃO}

$\mathrm{Na}$ Tabela 1, apresentam-se o poder calorífico superior e inferior, o teor de água, a massa específica aparente e a densidade energética das biomassas estudadas, bem como as eficiências energéticas do sistema, utilizando-se das diversas fontes de energia. Verifica-se que os primeiros valores são coerentes com os encontrados em literatura; entretanto, as eficiências calculadas podem ser melhoradas, uma vez que esses processos de conversão energética direta, isto é, gasificação com combustão adjacente dos gases, permitem atingir eficiências de até 90\%. Isso provavelmente ocorrerá com a redução das perdas térmicas nas câmaras de gaseificação e combustão, e otimização do ar primário e secundário, bem como da razão de equivalência para cada combustível em particular. 
TABELA 1. Poder calorífico superior e inferior, teor de água, massa específica aparente, densidade energética das biomassas, taxa de gaseificação e eficiência energética do sistema.

\begin{tabular}{lccccccc}
\hline Biomassa & $\begin{array}{c}\text { PCS } \\
\left(\mathrm{kJ} \mathrm{kg}^{-1}\right)\end{array}$ & $\begin{array}{c}\text { PCI } \\
\left(\mathrm{kJ} \mathrm{kg}^{-1}\right)\end{array}$ & $\begin{array}{c}\text { Umidade } \\
(\% \mathrm{bu})\end{array}$ & $\begin{array}{c}\text { Maspecífica } \\
\text { Aparente } \\
\left(\mathrm{kg} \mathrm{m}^{-3}\right)\end{array}$ & $\begin{array}{c}\text { Densidade } \\
\text { Energética } \\
\left(\mathrm{MJ} \mathrm{m}^{-3}\right)\end{array}$ & $\begin{array}{c}\text { Taxa de } \\
\text { Gaseificação } \\
\left(\mathrm{kg} \mathrm{s}^{-1}\right)\end{array}$ & $\begin{array}{c}\text { Eficiência } \\
\text { Energética }\end{array}$ \\
\hline $\begin{array}{l}\text { Tocos de } \\
\text { eucalipto }\end{array}$ & $18.789,1$ & $17.275,2$ & 13,8 & 273,2 & $4.719,70$ & 0,040 & 75,6 \\
$\begin{array}{l}\text { Restos de } \\
\text { serraria }\end{array}$ & $19.797,4$ & $18.268,8$ & 15,1 & 315,8 & $5.769,73$ & 0,042 & 60,1 \\
$\begin{array}{l}\text { Sabugos } \\
\text { de milho }\end{array}$ & $18.351,5$ & $16.799,8$ & 17,1 & 141,5 & $2.376,74$ & 0,051 & 52,8 \\
$\begin{array}{l}\text { Cavacos } \\
\text { de lenha }\end{array}$ & $18.240,0$ & $16.651,0$ & 15,7 & 268,0 & $4.200,41$ & 0,041 & 74,9 \\
\hline
\end{tabular}

Nas Figura 3; 4 e 5, apresentam-se as taxas de gaseificação e biomassa, isto é, o consumo de biomassas em função da vazão em massa, do ar primário, em $\mathrm{g} \mathrm{s}^{-1}$. Verifica-se que, aumentando a vazão de ar primário, aumenta-se a taxa de gaseificação. Isso indica a possibilidade de controlar a quantidade de energia produzida em determinado tempo, o que geralmente não é possível em fornalhas convencionais, tornando esse sistema mais adequado para onde se pretende secar diferentes quantidades de determinado produto por vez.

Ao comparar o consumo de combustível no sistema de gaseificação, de 15,3 a $18,8 \mathrm{k} \mathrm{h}^{-1}$, com aqueles obtidos por FREIRE (1998), que verificou, no mesmo secador, consumo de $26,8 \mathrm{~kg} \mathrm{~h}^{-1} \mathrm{de}$ lenha de eucalipto utilizando numa fornalha a fogo direto, verifica-se que todas as biomassas testadas no sistema gaseificador são viáveis como combustível para o gaseificador.

Taxa de gaseificação de sabugo de milho

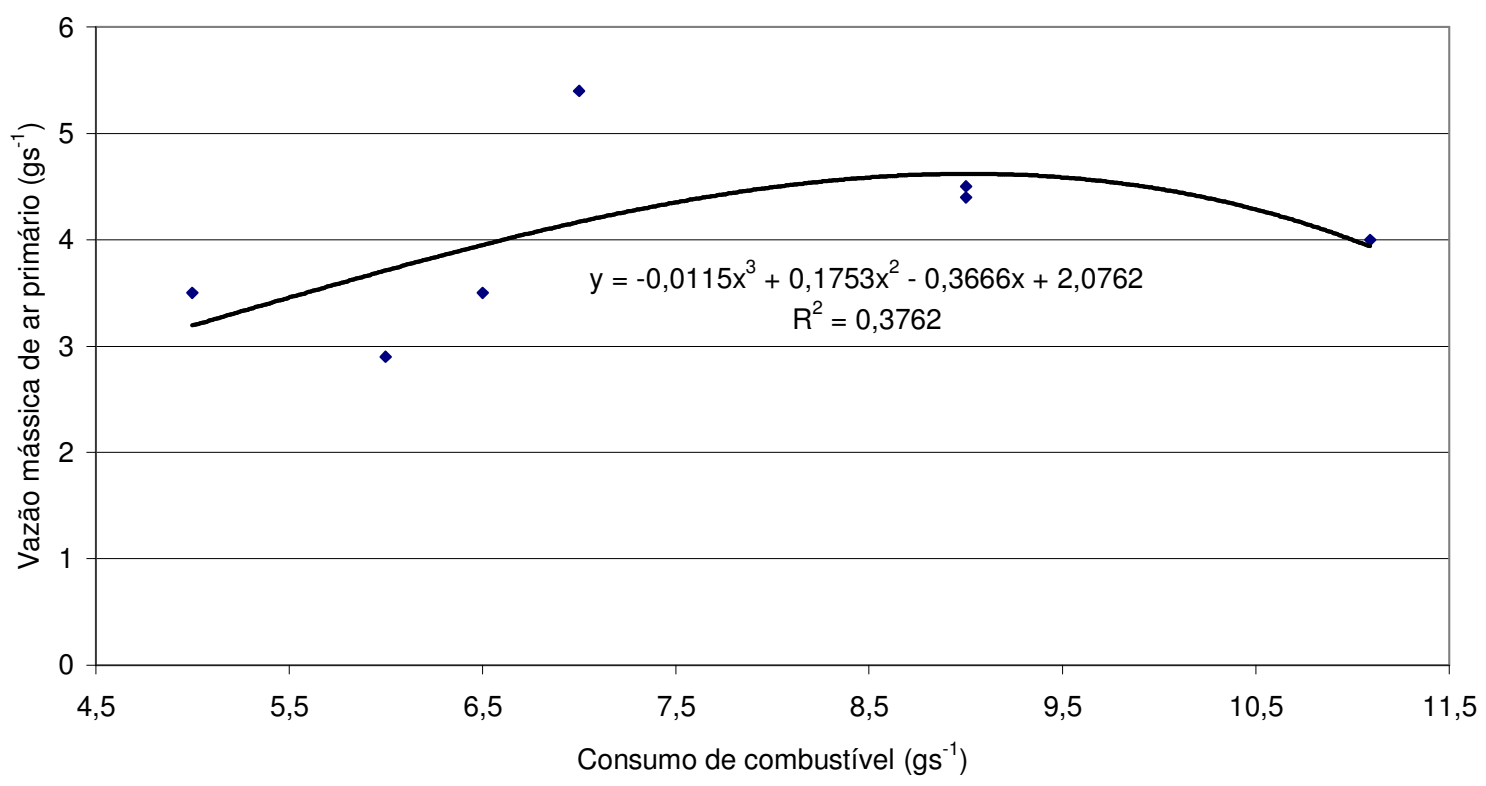

FIGURA 3. Consumo de biomassa de sabugo de milho, em função da vazão mássica de ar primário. 
Taxa de gaseificação de tocos de eucalipto

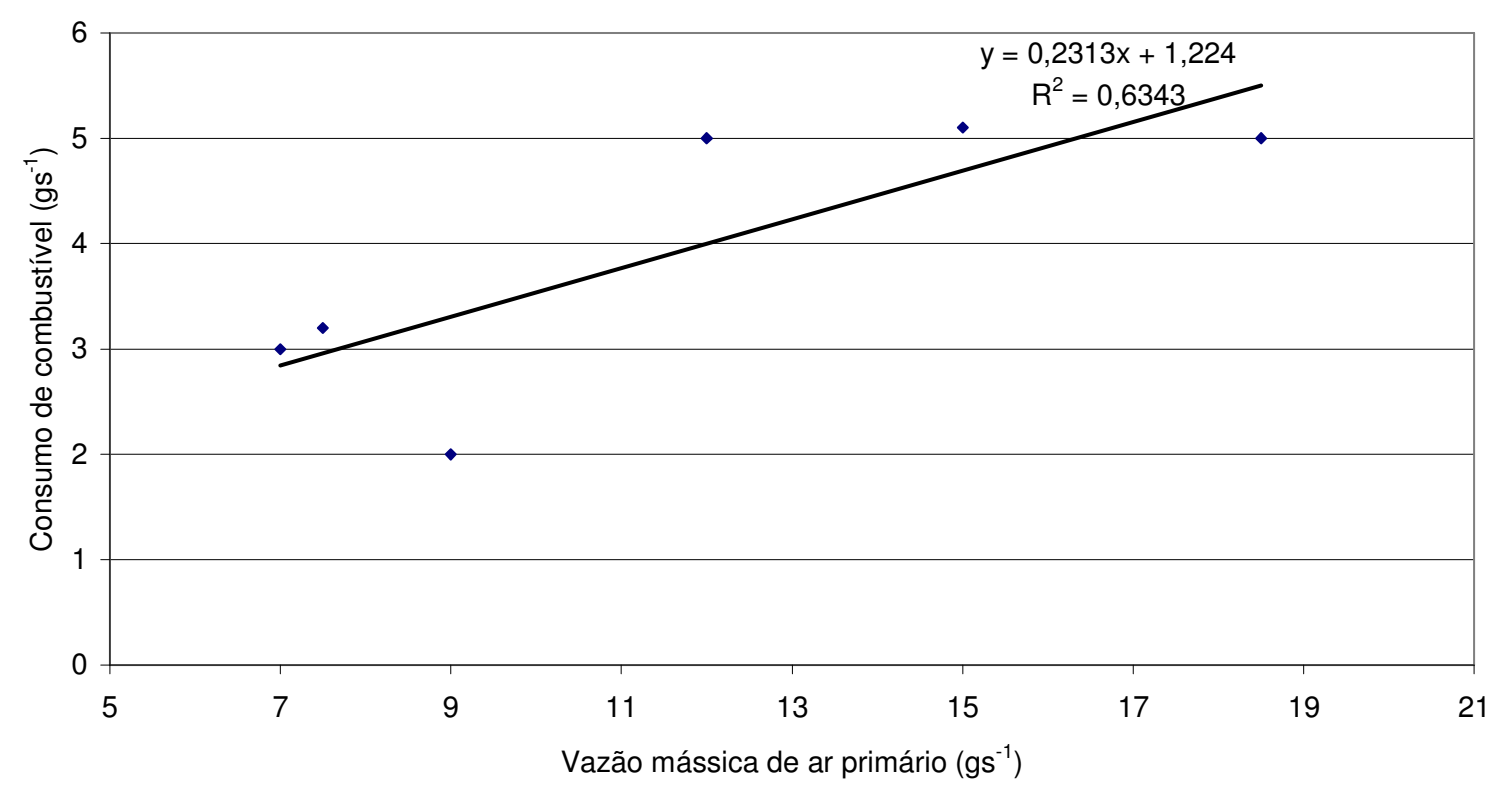

FIGURA 4. Consumo de biomassa de tocos de eucalipto, em função da vazão da massa de ar primário.

Taxa de gaseificação de madeiras de serraria

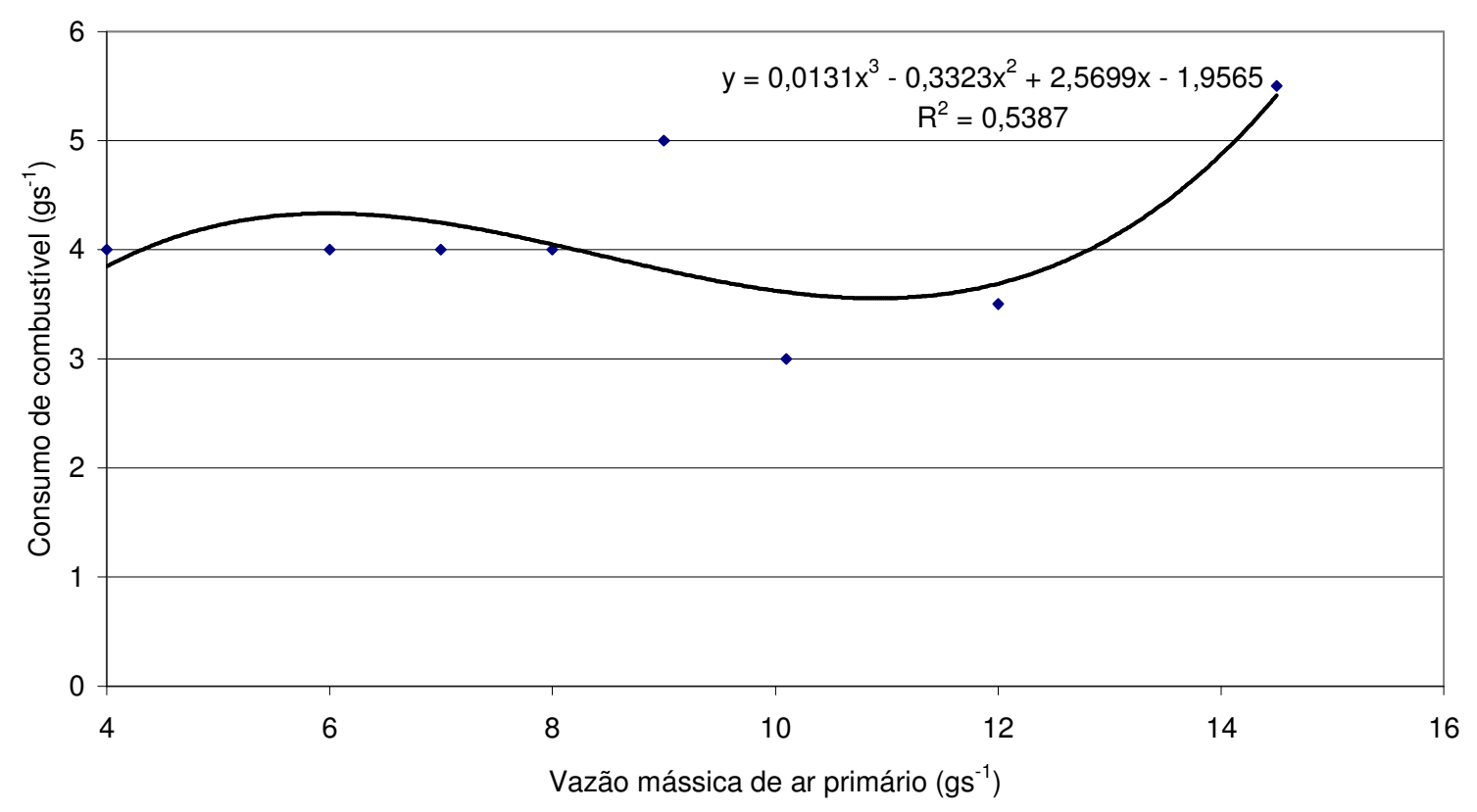

FIGURA 5. Consumo de biomassa de restos de madeira de serraria, em função da vazão da massa de ar primário.

A análise dos dados foi realizada dentro do conjunto domínio e imagem nos eixos das ordenadas e abscissas, respectivamente, evitando-se assim extrapolações dos dados plotados nos gráficos. 


\section{CONCLUSÕES}

Todas as biomassas testadas são viáveis como combustível para o gaseificador.

Dos combustíveis estudados, o resíduo de serraria foi o que apresentou maior poder calorífico inferior, maior massa específica aparente e maior densidade energética.

A taxa de gaseificação não aumentou significativamente com a variação de vazão mássica de ar primário.

A relativamente pequena densidade energética do sabugo resultou em baixo rendimento energético do sistema quando se usou esse combustível.

Aumentando-se a vazão mássica de ar, aumenta-se a taxa de gaseificação, indicando um possível controle da energia disponibilizada para secagem.

As eficiências energéticas de 75,6\% para tocos de eucalipto; 74,9\% usando-se cavacos de lenha; $60,1 \%$ para restos de serraria e $52,8 \%$ para sabugos de milho, mesmo que bastante superiores às das fornalhas de fogo indireto, indicam que ainda há, teoricamente, potencial para otimizar o sistema.

\section{REFERÊNCIAS BIBLIOGRÁFICAS}

SILVA, J.N. Gaseificação de biomassa para produção de calor. In: REUNIÃO DA SOCIEDADE BRASILEIRA PARA O PROGRESSO DA CIÊNCIA, 11., 1988, São Paulo. 1988.

CAMPOS, A.T. Desenvolvimento e análise de um protótipo de secador de camada fixa para café (Coffea arabica L.) com sistema de revolvimento mecânico. 1988. Dissertação (Mestrado) Universidade Federal de Viçosa, Viçosa- MG, 1998 .

FREIRE, A. T. Projeto e avaliação de um sistema de secagem combinado de café (Coffea arabica $L$.) despolpado. 1998. 98 f. Dissertação (Mestrado) - Universidade Federal de Viçosa, Viçosa - MG, 1998.

WYLEN, G.J. van; SONNTAG, R.E.; BORGNAKKE, C. Fundamentos da termodinâmica. 5.ed. São Paulo: Edgard Blücher, 1998. 537 p. 